\title{
Modelagem computacional no ensino de Física: favorecendo competências e concepções por parte de estudantes do Ensino Médio do CAp/UFRGS
}

Rafael Vasques Brandão*

\section{Problema de pesquisa}

Nas ciências naturais, modelagem pode ser entendida como o abrangente processo de construção, validação, uso e revisão de modelos científicos. Esses, por sua vez, podem ser entendidos como representaçôes simplificadas e idealizadas de sistemas, processos e fenômenos da natureza, aceitas por uma comunidade de cientistas. Tal processo é indispensável à construção do conhecimento científico, como enfatizam alguns filósofos da ciência (BUNGE, 1974; PATY, 1995; MORGAN; MORRISON, 1999).

$\mathrm{Na}$ Educação Básica em Ciências, modelagem pode ser entendida como a atividade de criação e exploração de versões didáticas de modelos científicos. Porém, tais atividades não costumam se constituir em práticas de sala de aula no Ensino Médio. Consequentemente, a maioria dos estudantes não reflete sobre a importância da modelagem na educação em Ciências, contexto em que também pode assumir um lugar de destaque, visto que, como sugerem Justi e Gilbert (2002): (a) 'aprender ciência' significa, em grande parte, conhecer os modelos concebidos pelos

* Professor de Física do Colégio de Aplicação da Universidade Federal do Rio Grande do Sul - CAp/UFRGS. Doutor em Ensino de Física pela UFRGS. E-mail: rafael. brandao@ufrgs.br 
cientistas, assim como as teorias, leis, princípios e conceitos de que fazem uso em suas construçôes; (b) 'aprender sobre ciência' é, em certa medida, refletir sobre o que versam os modelos científicos, sua natureza, funções, limitações e contexto histórico de desenvolvimento; e (c) 'aprender a fazer ciência' também é ser capaz de criar, testar e expressar seus próprios modelos.

A implementação de propostas capazes de promover um ensino de Ciências, centrado na estratégia da modelagem, exige, no entanto, a participação dos estudantes em atividades que propiciem a reflexão dos propósitos acima mencionados, imbricadas com o conteúdo de conhecimento a ser ensinado. Diversos estudos de natureza qualitativa (GROSSLIGHT et al., 1991; HARRISON; TREAGUST, 1996; GOBERT; PALLANT, 2004; WHITE; FREDERIKSEN, 1998; SCHWARZ; WHITE, 2005) e quantitativa (TREAGUST; CHITTLEBOROUGH; MAMIALA, 2002, 2004; CHITTLEBOROUGH et al., 2005) têm investigado os conhecimentos de estudantes da Educação Básica sobre modelos e modelagem científica. Os resultados têm demonstrado que a maioria dos estudantes analisados frequentemente: (a) concebe os modelos como 'cópias' da realidade; (b) não distingue entre o modelo e a realidade que ele representa, dificuldade que tende a se acentuar na medida em que a porção da realidade torna-se menos acessível à percepção; (c) manipula as expressões matemáticas relacionadas com os modelos sem reconhecer as entidades físicas a que se referem; (d) não reflete sobre o papel do cientista na construção dos modelos e da comunidade científica em suas validaçôes; e (e) tampouco reconhece o papel de mediação dos modelos entre teoria, experiência e simulação computacional acerca de sistemas, processos e fenômenos da natureza.

Frente a essa problemática, estratégias de ensino pautadas em diferentes perspectivas teóricas e metodológicas têm sido propostas para favorecer a aprendizagem da modelagem por parte de estudantes, tendo em vista os possíveis reflexos que uma compreensão adequada desse processo aporta à concepção 
de ciência daqueles que a dominam. Partindo dessa perspectiva, este projeto de pesquisa tem como objetivo investigar a aquisição de competências e concepções associadas à modelagem científica no ensino de Física por parte de estudantes do Ensino Médio do Colégio de Aplicação da UFRGS, à luz da teoria dos campos conceituais (TCC) de Gérard Vergnaud (1990, 1993).

A TCC parte do pressuposto de que o conhecimento está organizado em campos conceituais cujo domínio, por parte do sujeito, requer experiência, maturidade e aprendizagem de novas situações que pertençam ao domínio desse conhecimento. Campo conceitual é para Vergnaud "um conjunto informal e heterogêneo de problemas, situações, conceitos, relaçôes, estruturas, conteúdos e operações de pensamento, conectados uns aos outros e, provavelmente, entrelaçados durante o processo de aquisição" (VERGNAUD, 1982, p. 40).

A sua justificativa para a tese dos campos conceituais se apoia em três argumentos: (a) um conceito não se forma dentro de um só tipo de situação; (b) uma situação não se analisa com um só conceito; e (c) a construção e apropriação de todas as propriedades de um conceito ou de todos os aspectos de uma situação é um processo de larga duração, com avanços e retrocessos entre situações, concepções e competências.

Reside aí o motivo pelo qual os conceitos não podem ser reduzidos às suas definições, ainda mais quando se pensa no seu ensino e na sua aprendizagem. Para Vergnaud, os conceitos devem ser entendidos como um tripleto de conjuntos, $C=(S$, $I, R)$, em que: $S$ é o conjunto de situaçốes que dão sentido ao conceito $C$; I é o conjunto de invariantes (objetos, propriedades e relaçóes) que permite aos indivíduos operacionalizar o conceito de modo a lidar com as situações que compóem o conjunto $S$; e $R$ é o conjunto de representações simbólicas necessárias para indicar e representar o conjunto $I$ de invariantes e, por consequência, as situações que dão sentido ao conceito. $\mathrm{O}$ primeiro conjunto, de situaçóes, é o referente do conceito. O segundo, de invariantes operatórios, é o significado do conceito. Já o 
terceiro, de representações simbólicas, é o significante do conceito (VERGNAUD, 1983). Em termos psicológicos, o conjunto $S$ é a realidade e os conjuntos $I$ e $R$ a representação dessa realidade.

Entretanto o sentido atribuído aos conceitos não está propriamente nas situações nem mesmo na representação simbólica desses conceitos. O sentido está na interação do sujeito com as situações e com os significantes. Em outras palavras, são os esquemas utilizados pelo sujeito frente às situaçôes ou aos significantes que dão sentido a ambos para ele. Mais precisamente, esquema é "[...] uma organização invariante do comportamento para uma classe de situações determinada" (VERGNAUD, 1996, p. 201). O conceito piagetiano de esquema torna-se fundamental na TCC, visto que o desenvolvimento cognitivo consiste basicamente do repertório de esquemas que o sujeito possui para enfrentar uma determinada quantidade de situações, tratando-as como problemas passíveis de serem resolvidos. Nesse sentido, a tarefa mais importante do professor é a de propiciar oportunidades para que os estudantes desenvolvam seus esquemas de pensamento (VERGNAUD, 1988).

Embora o conceito de esquema possua definição precisa na teoria de Vergnaud é necessário aprofundar sua discussão, senão pela importância teórica que possui no vínculo entre o comportamento e a representação, mas pelo fato de que "[...] é nos esquemas que se devem pesquisar os conhecimentos-emação do sujeito, isto é, os elementos cognitivos que fazem com que a ação do sujeito seja operatória” (VERGNAUD, 1993, p. $2)$. Esses conhecimentos contidos implicitamente nos esquemas de pensamento são designados pelos termos conceito-em-ação e teorema-em-ação. São também conhecidos pela expressão geral invariantes operatórios. "Um teorema-em-ação é uma proposição considerada como verdadeira sobre o real. Um conceito-em-ação é uma categoria de pensamento considerada como pertinente" (VERGNAUD, 1996, p. 202). Os invariantes operatórios contidos nos esquemas são responsáveis pelo reconhecimento dos elementos relevantes à situação. A partir dessa informação é 
possível inferir a meta a ser atingida e as regras de ação necessárias para tal fim. Entretanto, os conceitos-em-ação e os teoremasem-ação não são tidos como verdadeiros conceitos e teoremas científicos, uma vez que esses são explícitos e, por isso, podem sofrer questionamentos quanto à sua pertinência e veracidade. Esse não é o caso dos conceitos e teoremas-em-ação que, por sua vez, permanecem, na maioria das vezes, largamente implícitos nos esquemas disponíveis do sujeito.

Cabe ao ensino de Ciências facilitar a transformação desse conhecimento implícito em conhecimento explícito, e cientificamente aceito, o que não ocorre de maneira abrupta e que de forma alguma é tarefa simples. O professor e a interação social entre os estudantes desempenham papel fundamental nesse processo de explicitação e compartilhamento do conhecimento.

A seguir, serão apresentados a justificativa, os objetivos, a metodologia e os resultados esperados e impactos dessa investigação.

\section{Justificativa}

A proposição básica que sustenta essa investigação pode ser enunciada da seguinte forma: para adquirir competências e concepções associadas à modelagem científica no ensino de Física é fundamental que o estudante do Ensino Médio domine um conjunto de situaçóes e problemas que requerem, por sua vez, o domínio de conceitos específicos, de naturezas distintas e inseparáveis da noção de modelo científico em Física, tais como: idealização, aproximação, referente, variável, parâmetro, domínio de validade, grau de precisão, expansão e generalização de modelos científicos. 


\section{Objetivos}

Com base nessa proposição, a investigação pretende contribuir para a linha de pesquisa sobre modelagem científica no ensino de Física, oferecendo respostas para as seguintes questốes de pesquisa.

- Quais os conhecimentos-em-ação ${ }^{3}$ que os estudantes do Ensino Médio do CAp/UFRGS fazem uso em atividades de modelagem computacional que envolvam um ou mais conceitos associados à noção de modelo científico, no campo conceitual da Mecânica?

- Quais desses conhecimentos-em-ação podem estar atuando como obstáculos epistemológicos à aquisição de competências e concepçôes associadas à modelagem científica no ensino de Física?

- De que as atividades de modelagem computacional favorecem a superação desses conhecimentos-em-ação?

Com base nas respostas às questões de pesquisa, a investigação culminará num estudo explanatório sobre os principais avanços e retrocessos na aprendizagem do processo de modelagem científica por parte dos estudantes do Ensino Médio do CAp/UFRGS. Mais precisamente, o produto final resultará no mapeamento dos conhecimentos-em-ação utilizados por estudantes do Ensino Médio em situação de modelagem computacional, no campo conceitual da Mecânica.

As hipóteses de partida da pesquisa baseiam-se em grande parte nos resultados apontados pela literatura especializada sobre o tema, expostos resumidamente na seção introdutória. Adicionalmente, deve-se salientar que:

- Os estudantes do Ensino Médio do CAp/UFRGS já devem possuir alguns conhecimentos-em-ação que se pretende

3 Os conhecimentos-em-ação se referem tanto às concepções, em geral expressas por meio de uma sequência de enunciados, quanto às competências, em geral expressas por meio de açôes julgadas adequadas para tratar uma situação. 
que eles evoquem e/ou dominem, porém, provavelmente não os usam para a aquisição de novas competências e concepções associadas à modelagem científica no ensino de Física;

- Os conhecimentos-em-ação dos estudantes devem estar fragmentados, sendo percebidos pelos mesmos em algumas situações de interesse da Mecânica, mas não em outras;

- Espera-se que a estratégia didática adotada favoreça a aquisição de competências e concepções não só para a resolução de situações-problema em Física, como também para a construção de uma visão de ciência mais próxima da prática científica moderna, cuja essência está na criação de modelos.

\section{Metodologia}

Segundo Vergnaud (1988), o estudo sistemático de um campo conceitual inicia com a identificação e a classificação de situaçóes potencialmente capazes de darem sentido aos conceitos que se pretende que os sujeitos dominem e que, consequentemente, possam facilitar o desenvolvimento cognitivo a partir do processo de conceitualização. Posteriormente, deve-se "[...] coletar dados sobre procedimentos e outras maneiras através das quais os estudantes expressam seu raciocínio" (VERGNAUD, 1988, p. 149). Assim, um ciclo de investigação tem início com o delineamento de situações e problemas e a correspondente identificação de invariantes operatórios, continuando com a construção de representações simbólicas a partir da observação e análise dos fenômenos que ocorrem. Então, com objetivo de melhorar o anterior, inicia-se um novo ciclo de investigação e assim por diante. Dessa forma, Vergnaud entende que o estudo de um campo conceitual é um programa que deve ser pensado a longo prazo.

Tendo em vista a abordagem canônica ao estudo de um campo conceitual proposta por Vergnaud e o problema de pesquisa caracterizado na seção introdutória, o enfoque metodológico da pesquisa possui um caráter eminentemente qualitativo. Mais 
especificamente, se pretende tratar cada estudante como um caso particular, visto que o interesse é nos esquemas de pensamento empregados pelos mesmos nas atividades de modelagem computacional, no contexto de uma disciplina de caráter eletivo intitulada Física no Computador: modelando a realidade de forma divertida, que será oferecida durante quatro semestres seguidos aos estudantes do segundo ano do Ensino Médio do CAp. Por isso, elegeu-se a estratégia de pesquisa de estudo de caso. $\mathrm{Na}$ acepção de Yin (2005), a estratégia de estudo de caso é definida por meio de dois enunciados técnicos:

1. Um estudo de caso é uma investigação empírica que investiga um fenômeno contemporâneo dentro de seu contexto da vida real, especialmente quando os limites entre o fenômeno e o contexto não estão claramente definidos (ibid., p. 32);

2. A investigação de estudo de caso enfrenta uma situação tecnicamente única em que haverá muito mais variáveis de interesse do que pontos de dados, e, como resultado, baseia-se em várias fontes de evidências, com os dados precisando convergir em um formato de triângulo, e, como outro resultado, beneficia-se do desenvolvimento prévio de proposiçôes teóricas para conduzir a coleta e a análise de dados (ibid., p. 33).

Em suma, buscar-se-á responder as questões de pesquisa propostas na seção anterior, com base na proposição que sustenta esta investigação, adequando-se as hipóteses de partida às evidências encontradas sobre o fenômeno de interesse e tentando excluir possíveis hipóteses explicativas concorrentes. Até quando esta tarefa teoricamente interminável será conduzida, dependerá basicamente da adequação dos instrumentos para coleta de dados. Nesse sentido, Yin argumenta que, na sua visão, estudos de caso: (a) da mesma forma que os experimentos em Ciências Sociais, são generalizáveis a proposições teóricas, e não a populações ou universos; e (b) não precisam demorar muito tempo: o pensamento contrário decorre da confusão entre o método de estudo de caso com um método específico de coleta de dados, como etnografia ou observação participante (YIN, 2005, p. 29-30).

Para tanto, a coleta de dados estará baseada, fundamentalmente: 
- em observações dos estudantes 'em situação', ou seja, em atividade de modelagem com auxílio do computador;

- nos registros escritos de avaliações e guias de atividades confeccionados para as atividades de modelagem, individuais e coletivas;

- em gravações em áudio e/ou vídeo das discussões entre estudantes em situação e desses com o professor;

- em entrevistas semiestruturadas individuais.

Resumidamente, se pretende observar, registrar e documentar todo o tipo de material que sirva de subsídio para unir de forma lógica os dados às proposições, resultando num estudo de caráter explanatório sobre os conhecimentos-em-ação dos estudantes do Ensino Médio do CAp-UFRGS acerca da modelagem científica no campo conceitual da Mecânica.

\section{Resultados esperados e impactos}

A expectativa desse projeto de pesquisa é que a aprendizagem do processo de modelagem científica no ensino de Física por parte do estudante do Ensino Médio do CAp-UFRGS possa impactar positivamente:

- a aquisição de concepções sobre a natureza e a construção do conhecimento científico;

- a instrumentalização para o desenvolvimento de competências computacionais; $\mathrm{e}$

- a contextualização do conhecimento em Física num cenário mais amplo de alfabetização científica de cidadãos do mundo. 


\section{Referências}

BUNGE, Mário. Teoria e realidade. São Paulo: Editora Perspectiva, 1974.

CHITTLEBOROUGH, Gail Diane; TREAGUST, David F.; MAMIALA, Thapelo L.; MOCERINO, Mauro. Students' perceptions of the role of models in the process of science and in the process of learning. Research in Science \& Technological Education, v. 23, n. 2, p. 195-212, 2005.

GOBERT, Janice D.; PALLANT, Anne. Fostering student's epistemologies of models via authentic model-based tasks. Journal of Science Education and Technology, v. 13, n. 1, p. 7-22, 2004.

GROSSLIGHT, Lorraine; UNGER, Christopher; JAY, Eileen; SMITH, Carol L. Understanding models and their use in science: conceptions of middle and high school students and experts. Journal of Research in Science Teaching, v. 28, n. 9, p. 799-822, 1991.

HARRISON, Allan G.; TREAGUST, David F. Secondary students' mental models of atoms and molecules: implications for teaching chemistry. Science Education, v. 80, n. 5, p. 509-534, 1996.

JUSTI, Rosária da Silva; GILBERT, John K. Science teachers' knowledge about and attitudes towards the use of models and modelling in learning science. International Journal of Science Education, v. 24, n. 12, p. 12731292, 2002.

MORGAN, Mary S.; MORRISON, Margaret. Models as mediators: perspectives on natural and social science. Cambridge: Cambridge University Press, 1999.

PATY, Michel. A matéria roubada: a apropriação crítica do objeto da física contemporânea. São Paulo: Editora da Universidade de São Paulo, 1995.

SCHWARZ, Christina V.; WHITE, Barbara Y. Metamodeling knowledge: developing student's understanding of scientific modeling. Cognition and Instruction, v. 23, n. 2, p. 165-205, 2005.

TREAGUST, David F.; CHITTLEBOURGH, Gail D.; MAMIALA, Thapelo L. Students' understanding of the role of scientific models in learning science. International Journal of Science Education, v. 24, n. 4, p. $357-368,2002$. 
TREAGUST, David F.; CHITTLEBOURGH, Gail D.; MAMIALA, Thapelo L. Students' understanding of the descriptive and predictive nature of teaching models in organic chemistry. Research in Science Education, v. 34, n. 1, p. 1-20, 2004.

VERGNAUD, Gérard. A classification of cognitive tasks and operations of thought involved in addition and subtraction problems. In: T. P. Carpenter; J. M. Moser; T. A. Romberg (Eds.). Addition and Subtraction: a cognitive perspective, p. 39-59. Hillsdale: Lawrence Erlbaum, 1982.

. Quelques problèmes theóriques de la didactique a propos d'un example: les structures additives. Atelier International d'été: Recherche en Didactique de la Physique. La Londe les Maures, França, 26 de junho a 13 de julho, 1983.

. Multiplicative structures. In: HIEBERT, H.; BEHR, M (Eds.). Research Agenda in Mathematics Education. Number Concepts and Operations in the Middle Grades, p. 141-161. Hillsdale: Lawrence Erlbaum, 1988.

. La théorie des champs conceptuels. Recherches en Didactique des Mathématiques, v. 10, n. 2-3, p. 133-170, 1990.

. Teoria dos campos conceituais. In: Seminário Internacional de Educação Matemática, 1., 1993, Rio de Janeiro. Anais do $1^{\circ}$ Seminário Internacional de Educação Matemática, Rio de Janeiro: NASSER, L., 1993. p. 1-26.

. A trama dos campos conceituais na construção dos conhecimentos. Revista do GEEMPA, v. 4, p. 9-19, 1996.

. Activité humaine et conceptualisation: questions à Gérard Vergnaud. Toulouse: Presses Universitaires du Mirail, 2007.

WHITE, Barbara Y.; FREDERIKSEN, John R. Inquiry, modeling, and metacognition: making science accessible to all students. Cognition and Instruction, v. 16, n. 1, p. 3-188, 1998.

YIN, Robert K. Estudo de caso: planejamento e métodos. Porto Alegre: Bookman, 2005. 